\title{
Independence of yield potential and crop nitrogen response
}

\author{
William R. Raun · John B. Solie • Marvin L. Stone
}

(C) Springer Science+Business Media, LLC 2010

\begin{abstract}
Crop yield level and nitrogen (N) responsiveness influence the demand for fertilizer. If they were found to be unrelated, this would justify using a combination of both for determining fertilizer $\mathrm{N}$ requirements. Failure to understand the independence of crop response to $\mathrm{N}$ and yield level has led to confusion as to what theory is appropriate for making $\mathrm{N}$ fertilizer rate recommendations. The sufficiency approach applies a fixed rate of $\mathrm{N}$ at a computed sufficiency level, regardless of yield potential. Alternatively, mid-season optical sensor estimates of yield potential and crop response to additional $\mathrm{N}$ provide a physiological basis to estimate $\mathrm{N}$ removal and a biologically based $\mathrm{N}$ application rate. This study investigated the relationship between grain yield and response to $\mathrm{N}$ in long-term wheat and corn experiments. No relationship between response to $\mathrm{N}$ and grain yield was found. There was also no relationship between yield and year at two of three sites. Finally, there was no relationship between response to $\mathrm{N}$ and year at any site. Because yield and response to $\mathrm{N}$ were consistently independent of one another, and as both affect the demand for fertilizer $\mathrm{N}$, estimates of both should be combined to calculate realistic in-season $\mathrm{N}$ rates.
\end{abstract}

Keywords Nitrogen - Yield potential - Sufficiency - Recommendations - Sensor-based · Nitrogen response $\cdot$ Nitrogen recommendations $\cdot$ Nitrogen fertilizer rates

\section{Introduction}

With the advent of advanced sensor-based methods for improving the efficiency of fertilizer $\mathrm{N}$ use, algorithms have been developed that fail to account for accepted fundamental

W. R. Raun $(\bowtie)$

Department of Plant and Soil Sciences, Oklahoma State University, 044 N. Ag Hall, Stillwater, OK 74078, USA

e-mail: bill.raun@okstate.edu

J. B. Solie · M. L. Stone

Department of Biosystems and Agricultural Engineering, Oklahoma State University, 044 N. Ag Hall, Stillwater, OK 74078, USA 
concepts and theories on nutrient management. Current use of indirect measurements to estimate biological parameters, e.g. biomass estimated from NDVI of an optical sensor, requires caution before applying this methodology to estimate fertilizer $\mathrm{N}$ rates. The same fundamental theories, such as Bray's mobility concept (Bray 1954), that restricted the use of sufficiency theory to immobile nutrients such as phosphorus still apply to current new sensing methods.

Yield potential $\left(\mathrm{YP}_{0}\right)$ is defined as the potential grain yield that is achievable with no additional $\mathrm{N}$ fertilizer applied (Raun et al. 2002). Yield potential is known to change from 1 year to the next because temporal variability, i.e. rainfall, temperature, relative humidity and so on, can vary considerably from year to year (Girma et al. 2007a, b). Consequently, yield potential is specific to the season for which it is being evaluated.

New sensing technologies are being developed to measure plant properties directly or indirectly. Among them is the measurement of reflected or transmitted light at specific wave lengths. Girma et al. (2006) showed that mid-season normalized difference vegetative index (NDVI) calculated from optical sensor measurements and plant height were good predictors of final winter wheat grain yield. Earlier work by Lukina et al. (2001) showed that early-season NDVI alone was a good predictor of final winter wheat grain yield over several locations and years. However, improved prediction of yield was found when readings from later in the season were used.

Johnson and Raun (2003) first discussed the use of the harvest response index ( $\left.\mathrm{RI}_{\text {Harvest }}\right)$ to predict additional $\mathrm{N}$ requirements. The $\mathrm{RI}_{\text {Harvest }}$ was calculated by dividing the maximum yield of fertilized plots by the yield of unfertilized plots. This was then used to estimate the response of the crop to additional $\mathrm{N}$ for a given year. Mullen et al. (2003) showed that the RI (yield in the high $\mathrm{N}$ plot, divided by the control or farmer practice) could be predicted using mid-season optical sensor based NDVI measurements recorded from the same plots (NDVI in the high $\mathrm{N}$ plot divided by the control or farmer practice). This ratio was termed $\mathrm{R}_{\mathrm{INDVI}}$. As for the year to year changes in yield, $\mathrm{RI}_{\mathrm{NDVI}}$ was found to be unpredictably variable (Johnson and Raun 2003).

Bray (1954) noted that Liebig's law of the minimum could be interpreted as meaning that the crop consumed all the deficient nutrient in the soil, making yield directly proportional to the amount of the deficient nutrient present, and that in the crop. Later work by Bray noted that nitrogen follows Liebig's law of the limiting nutrient because a given level of nitrate nitrogen can be more than adequate for the first stages of growth, yet can become highly deficient later and limit yield to a certain value (Bray 1962). He further stated that not all nutrient forms can follow a percentage sufficiency concept such as that used for phosphorus. Moreover, the relatively mobile nutrients such as $\mathrm{N}$ should follow the law of the limiting nutrient, not sufficiency.

Several agronomists and engineers are attempting to use direct and indirect measurements of crop parameters from newly developed sensors to predict additional nitrogen requirements for crops. Frequently, proposed algorithms to calculate $\mathrm{N}$ rates are empirical and do not account for temporal variability in crop growth and yield. Specifically, these algorithms do not account for the effects of temporal variability in available $\mathrm{N}$ in the crop's environment, particularly available moisture and the consequent temporal variability in crop yield. The objectives of this study were to determine if grain yield was related to $\mathrm{N}$ responsiveness, and if there was any relationship between response to $\mathrm{N}$, grain yield and time. 


\section{Materials and methods}

The response index (RI) was computed by year from three long-term experiments, two in Oklahoma and one in Nebraska, whereby the yield of the high $\mathrm{N}$ treatment was divided by that of the low $\mathrm{N}$ treatment. The three long-term experiments were Experiment 222, Experiment 502 (both winter wheat in Oklahoma) and Mead (long-term corn trial in Nebraska). Experiments 222 and 502 were established in 1969 and 1970, respectively, under conventional tillage. Experiment 222 is at the Agronomy Research Station in Stillwater, OK at an altitude of 272 masl on a well drained, very deep and very slowly permeable Kirkland silt loam (fine, mixed, thermic Udertic Paleustoll). Experiment 502 is located at the North Central Research Station in Lahoma, OK at an altitude of 396 masl on a well drained, deep and moderately permeable Grant silt loam (fine-silty, mixed, thermic Udic Argiustoll). The one corn experiment was established in 1969 and was continued until 1983 on a Sharpsburg silty clay loam (fine, montmorillonitic, mesic Typic Argiudoll) at the Nebraska Agricultural Experiment Station Field Laboratory near Mead, NE at an altitude of 342 masl. Fertilizer was applied at rates of $0,90,180$ and $270 \mathrm{~kg} \mathrm{~N}^{-1}$ to plots of $9.1 \times 20 \mathrm{~m}$. Plot details, planting and the management associated with this trial are reported in Olson et al. (1986). The average annual precipitation at Stillwater and Lahoma is 80 and $72 \mathrm{~cm}$ at Mead, NE. The experimental design was a randomized complete block with four replications in all experiments. There were 12 and 13 treatments that comprised application of different rates of N, P and K fertilizers included in Exp. 222 and 502, respectively. Nitrogen, $\mathrm{P}$ and $\mathrm{K}$ were applied as ammonium nitrate $(34 \% \mathrm{~N})$, triple super phosphate $(20 \% \mathrm{P})$ and potassium chloride $(53 \% \mathrm{~K})$, respectively, in both experiments. Plots are permanent from year to year and have received fixed rates of $\mathrm{N}, \mathrm{P}$ and $\mathrm{K}$ every year. The treatments used to determine the response index and yield potential (high preplant $\mathrm{N}$ rate) were 90-29-37 and 0-29-37 (N-P-K) at Experiment 222, and 112-20-56 and 0-20-56 (NPK) at Experiment 502. Individual plots at Stillwater were $6.1 \times 18.3 \mathrm{~m}$ and $4.9 \times 18.3 \mathrm{~m}$ at Lahoma. Experimental plots were conventionally tilled every year in the summer to a depth of $15 \mathrm{~cm}$ using a disk plow. Plots were then harrowed before fertilizer application using a spike tooth harrow every year. Winter wheat was planted continuously for 38 (Stillwater) and 37 (Lahoma) years in 25.4-cm wide rows at seeding rates of $67 \mathrm{~kg} \mathrm{ha}^{-1}$. In some years, the seeding rate was increased to $110 \mathrm{~kg} \mathrm{ha}^{-1}$ in anticipation of poor germination and emergence due to unfavorable soil moisture conditions at seeding. Since 1992, winter wheat has been planted in 19-cm rows at Stillwater. At the Oklahoma locations, varieties were changed with time to take advantage of increased genetic yield potential, and the need for resistance to rust (Table 1). In both these experiments, fertilizer was broadcast before planting and incorporated into the soil in late August to midSeptember. Winter wheat was planted in late September to early October every year, and corn was planted in April-May. Grain yield data were recorded for each plot and year using a self propelled combine at all sites.

From the long-term data base from all trials, $\mathrm{RI}_{\text {Harvest }}$ was computed by dividing the high $\mathrm{N}$ treatment yield by that of the control plot with no fertilizer $\mathrm{N}$. Treatments resulting in maximum yields did not always correspond with the high $\mathrm{N}$ rate. In some years, maximum yields were observed at very low rates of N. All linear regression analyses with yield used maximum yields for each year irrespective of the $\mathrm{N}$ treatment they had received. The latter condition ensured that plots of maximum yields versus RIs avoided potential autocorrelation because of how the RI was computed. In addition, maximum grain yield and $\mathrm{RI}_{\text {Harvest }}$ were plotted against year or time. 
Table 1 Regression model results of $R^{2}$, slope and slope significance for the relationships between $\mathrm{RI}_{\mathrm{Harvest}}$ and grain yield, year and grain yield, and year and $\mathrm{RI}_{\text {Harvest }}$, for Experiment 502, Experiment 222 and Mead, $\mathrm{NE}$

\begin{tabular}{|c|c|c|c|c|c|}
\hline \multirow[t]{2}{*}{ Experiment } & \multicolumn{2}{|l|}{ Variables } & \multirow[t]{2}{*}{ Slope } & \multirow{2}{*}{$\begin{array}{l}\text { Slope } \\
\text { significance } \\
\text { pr }>|t|\end{array}$} & \multirow[t]{2}{*}{ Model $R^{2}$} \\
\hline & Independent & Dependent & & & \\
\hline Experiment 502 & $\mathrm{RI}_{\text {Harvest }}$ & Grain Yield & 565 & 0.011 & 0.17 \\
\hline Experiment 222 & $\mathrm{RI}_{\text {Harvest }}$ & Grain Yield & 289 & 0.108 & 0.07 \\
\hline Mead, NE & $\mathrm{RI}_{\text {Harvest }}$ & Grain Yield & -107 & 0.730 & 0.01 \\
\hline Experiment 502 & Year & Grain Yield & 39 & 0.001 & 0.22 \\
\hline Experiment 222 & Year & Grain Yield & -0.61 & 0.958 & 0.00 \\
\hline Mead, NE & Year & Grain Yield & -45 & 0.335 & 0.05 \\
\hline Experiment 502 & Year & $\mathrm{RI}_{\text {Harvest }}$ & 0.018 & 0.086 & 0.09 \\
\hline Experiment 222 & Year & $\mathrm{RI}_{\text {Harvest }}$ & 0.028 & 0.007 & 0.20 \\
\hline Mead, NE & Year & $\mathrm{RI}_{\text {Harvest }}$ & 0.033 & 0.380 & 0.06 \\
\hline
\end{tabular}

pr $>|t|$-probability of obtaining a greater absolute value of $t$

\section{Results}

At two of the three sites, there was no relationship between the response index and grain yield (Table 1). For Experiment 502, the linear slope is significant but the model explains only $17 \%$ of the observed variation (Fig. 1). The regression slope for Experiment 222 (wheat) is slightly positive and for Mead, NE (corn) it is slightly negative, but at neither location is the slope of the linear model significant (Figs. 2, 3, respectively). Overall these data show that grain yield over these sites and years is not related to $\mathrm{N}$ responsiveness or RI.

Grain yield was plotted against crop year to determine if long term trends in yield affect grain yield at all three sites. There is no relationship between yield and crop year at Experiment 222 and Mead, NE sites (Figs. 5, 6, respectively). However, yield increases slightly with crop year at Experiment 502 (Fig. 4). This is probably due to the changes in

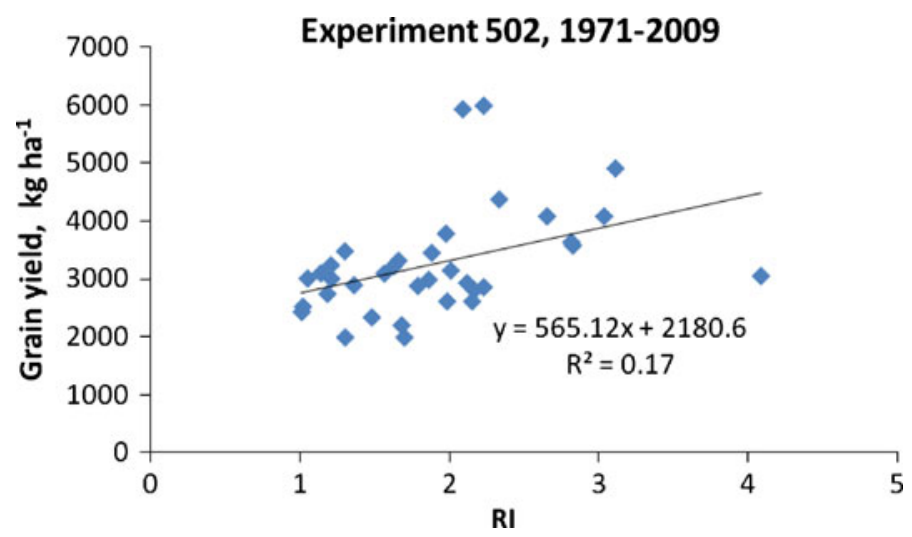

Fig. 1 Relationship between the response index (RI) and maximum yield of winter wheat at Experiment 502 near Lahoma, OK, 1970-2008 


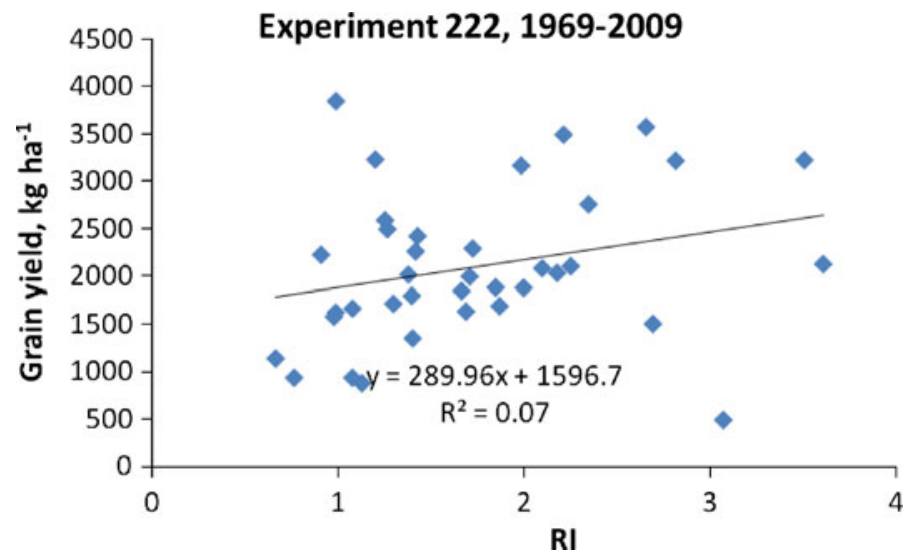

Fig. 2 Relationship between the response index (RI), and maximum yield of winter wheat at Experiment 222, Stillwater, OK, 1969-2008

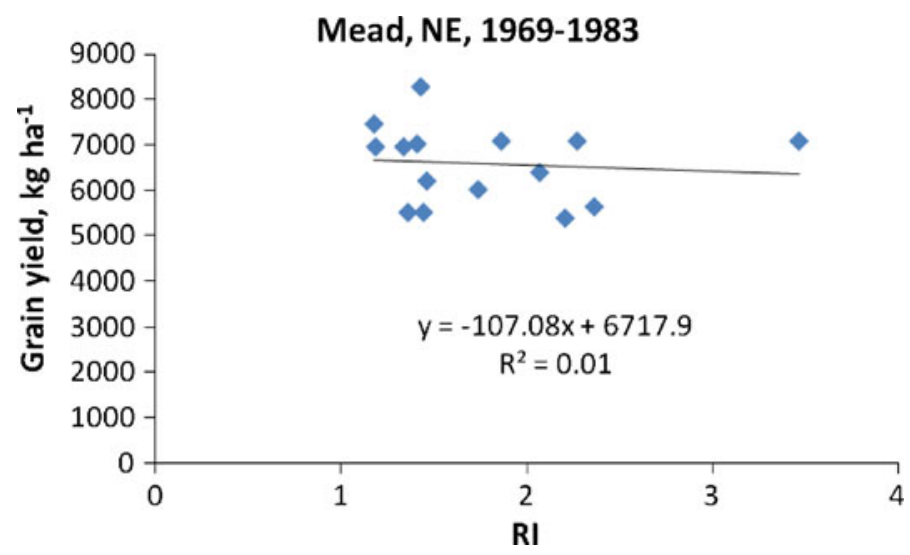

Fig. 3 Relationship between the response index (RI), and maximum yield of corn at Mead, NE, 1969-1983

varieties with higher yield potential in later years of the experiment (Table 2). However, the linear model for yield and year explains only $26 \%$ of the variability. Grain yields ranged from 440 to $3561 \mathrm{~kg} \mathrm{ha}^{-1}$ at Experiment 222 over 38 years, from 1420 to $5930 \mathrm{~kg} \mathrm{ha}^{-1}$ at Experiment 502 over 40 years and from 5393 to $8279 \mathrm{~kg} \mathrm{ha}^{-1}$ at Mead, NE over 14 years. Nitrogen removal using an average $2.39 \% \mathrm{~N}$ in wheat grain and $1.19 \% \mathrm{~N}$ in corn grain ranged from 10 to 85, 34 to 142, and 64 to $99 \mathrm{~kg} \mathrm{ha}^{-1}$ at Experiment 222, Experiment 502 and Mead, NE, respectively. This broad range over time shows clearly why $\mathrm{N}$ demand must also be different over years, and ultimately related to local environmental conditions.

Crop year as a function of $\mathrm{RI}_{\text {Harvest }}$ is marginally significant for Experiment 502, significant for Experiment 222 and not significant at Mead (Figs. 7, 8 and 9, respectively; Table 1). As for observations of yield with time, the response index or $\mathrm{N}$ responsiveness varies with time and is unpredictable. The trend was small with an increase of $0.01 \rightarrow 0.03$ RI per year. This small overall increase in responsiveness could be because these are long-term plots where $\mathrm{N}$ depletion would be expected in the $0-\mathrm{N}$ control plot. The linear model explains only 


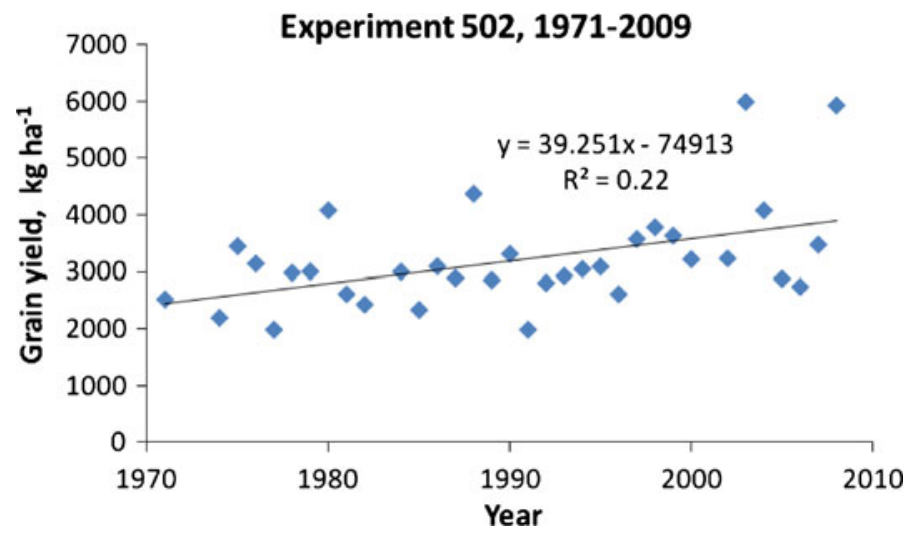

Fig. 4 Relationship between maximum grain yield and time (year) for the long-term winter wheat Experiment 502, near Lahoma, OK, 1970-2008

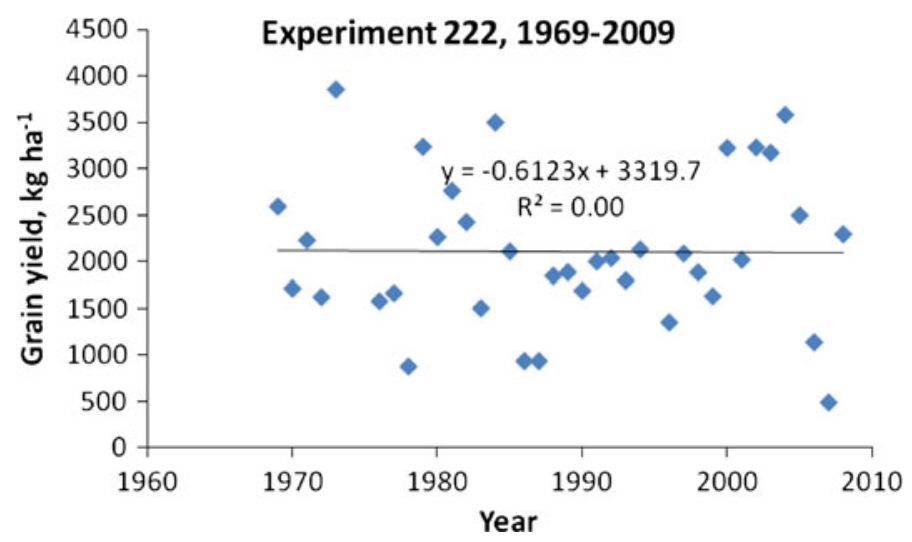

Fig. 5 Relationship between maximum grain yield and time (year) for the long-term winter wheat Experiment 222, Stillwater, OK, 1969-2008

$19 \%$ of the variability for Experiment 222 (Table 1). At best, the response index was only marginally related to crop year. In several 2-year sequences at Experiment 222, high $(>1.5)$ $\mathrm{RI}_{\text {Harvest }}$ or $\mathrm{N}$ responsiveness was seen in ensuing years. Similarly, low crop response to $\mathrm{N}$ in two consecutive years also occurs (Figs. 7-9). Combined, these two observations indicate the unpredictability of $\mathrm{N}$ responsiveness with time. With only a marginal relationship between grain yield and the response index with time shows that yield and $\mathrm{N}$ responsiveness depend upon the year in which they were evaluated. Equally important was that there is no trend visible over years or from 1 year to the next that could be used to predict yield potential and or $\mathrm{N}$ responsiveness (Figs. 7-9).

\section{Discussion}

So, why is it important to show that yield and $\mathrm{N}$ responsiveness are independent of one another? If they are independent of one another, and if they are to be estimated, they must 


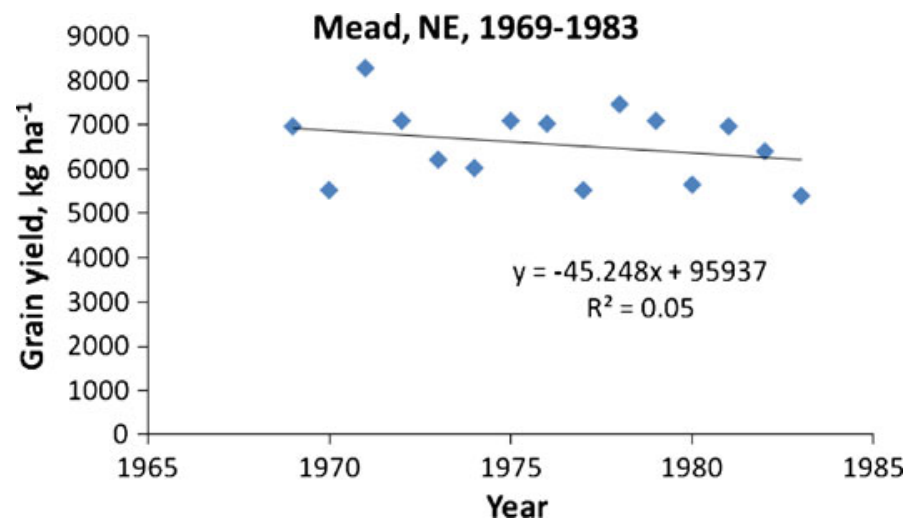

Fig. 6 Relationship between maximum grain yield and time (year) for the long-term corn experiment at Mead, NE, 1969-1983

be determined separately. Any practice that combines the two without considering their independence can create large errors in $\mathrm{N}$ application rates. An example of where yield and $\mathrm{N}$ responsiveness was not partitioned was in the use of a sufficiency concept for recommending the application of added fertilizer N (Varvel et al. 2007). This procedure used normalized chlorophyll meter readings and relative or normalized yields. If yield and $\mathrm{N}$ responsiveness are independent of one another, and both vary significantly year to year, using of a sufficiency index (SI or normalized chlorophyll meter readings to obtain $\mathrm{N}$ responsiveness) disregards the variability in $\mathrm{N}$ response and yield, which are both dependent on the environment (year), Figs. 7, 8 and 9. In the sufficiency approach, the final $\mathrm{N}$ rate recommended is fixed to a percentage sufficiency and not to the yield potential that could be achieved that year. Knowing the potential yield is fundamental for calculating total $\mathrm{N}$ demand of cereal crops. This is relevant because various authors have shown that early-season normalized difference vegetation index (NDVI) sensor readings can be used to predict yield potential for corn and wheat (Teal et al. 2006; Raun et al. 2001; Hochheim and Barber 1998). Mullen et al. (2003) further showed that $\mathrm{N}$ responsiveness or the response index can be predicted from early season NDVI readings.

The wide range in $\mathrm{N}$ removal over time observed in both trials suggests that farmers would be unlikely to apply the same rate of $\mathrm{N}$ each year if they had this knowledge. If the upper boundary on achievable yield potential changes yearly and also the demand for fertilizer $\mathrm{N}$, the obvious solution for improving fertilizer $\mathrm{N}$ rate recommendations is to be able to predict both yield potential and $\mathrm{N}$ responsiveness or the response index independently. Once these have been predicted independently of one another, the next step is to combine them into a meaningful algorithm that will give a mid-season estimate of the additional fertilizer $\mathrm{N}$ needed to achieve maximum yields. As Raun et al. (2005) showed, the yield achievable with added fertilizer $\mathrm{N}$ is the product of estimated yield potential (YP0) and the response index (RI) and given as YPN. The final fertilizer $\mathrm{N}$ rate is determined by subtracting $\mathrm{N}$ uptake at YP0 from $\mathrm{N}$ uptake at YPN, divided by an expected use efficiency. Nitrogen uptake is estimated using an average percentage $\mathrm{N}$ in the grain for the crop in question. For winter wheat this is approximately $2.39 \%$, and $1.19 \%$ for corn.

The range in $\mathrm{N}$ demand ( $\mathrm{N}$ uptake in the high $\mathrm{N}$ plot minus $\mathrm{N}$ uptake in the low $\mathrm{N}$ plot divided by an efficiency factor of 0.5 , assuming that $\mathrm{N}$ would be applied as a conventional inorganic fertilizer) was from 0 to $156 \mathrm{~kg} \mathrm{~N} \mathrm{ha}^{-1}$, with an average of $56 \mathrm{~kg} \mathrm{~N} \mathrm{ha}^{-1}$ at 
Table 2 Winter wheat varieties planted in Experiments 222 and 502 from 1969 to present

\begin{tabular}{|c|c|c|}
\hline Year & $\begin{array}{l}\text { Experiment } 502 \\
\text { Variety }\end{array}$ & $\begin{array}{l}\text { Experiment } 222 \\
\text { Variety }\end{array}$ \\
\hline 1969 & - & Scout 66 \\
\hline 1970 & - & Scout 66 \\
\hline 1971 & Scout 66 & Scout 66 \\
\hline 1972 & Scout 66 & Scout 66 \\
\hline 1973 & Scout 66 & Scout 66 \\
\hline 1974 & Scoun 66 & Scout 66 \\
\hline 1975 & Triumph 64 & Triumph 64 \\
\hline 1976 & Triumph 64 & Triumph 64 \\
\hline 1977 & Osage & Triumph 64 \\
\hline 1978 & Osage & Osage \\
\hline 1979 & TAM 101 & Osage \\
\hline 1980 & TAM 101 & Osage \\
\hline 1981 & TAM 101 & TAM 101 \\
\hline 1982 & TAM 101 & TAM 101 \\
\hline 1983 & TAM 101 & TAM 101 \\
\hline 1984 & TAM 101 & TAM 101 \\
\hline 1985 & TAM 101 & TAM 101 \\
\hline 1986 & TAM 101 & TAM 101 \\
\hline 1987 & TAM 101 & TAM 101 \\
\hline 1988 & TAM 101 & TAM 101 \\
\hline 1989 & TAM 101 & TAM 101 \\
\hline 1990 & TAM 101 & TAM 101 \\
\hline 1991 & TAM 101 & TAM 101 \\
\hline 1992 & TAM 101 & TAM 101 \\
\hline 1993 & Karl & Karl \\
\hline 1994 & Karl & Karl \\
\hline 1995 & Tonkawa & Tonkawa \\
\hline 1996 & Tonkawa & Tonkawa \\
\hline 1997 & Tonkawa & Tonkawa \\
\hline 1998 & Tonkawa & Tonkawa \\
\hline 1999 & Tonkawa & Tonkawa \\
\hline 2000 & Custer & Custer \\
\hline 2001 & Custer & Custer \\
\hline 2002 & Custer & Custer \\
\hline 2003 & Custer & Custer \\
\hline 2004 & Custer & Custer \\
\hline 2005 & Overley & P2174 \\
\hline 2006 & Overley & Endurance \\
\hline 2007 & Overley & Endurance \\
\hline 2008 & Overley & OK Field \\
\hline
\end{tabular}

Experiment 502, 0 to $110 \mathrm{~kg} \mathrm{~N}^{-1}$ with an average of $35 \mathrm{~kg} \mathrm{~N} \mathrm{ha}^{-1}$ at Experiment 222 and 26 to $172 \mathrm{~kg} \mathrm{~N}^{-1}$ with an average of $81 \mathrm{~kg} \mathrm{~N}^{-1}$ at Mead, NE. These values were based on experiments over 37, 38 and 15 years (Experiment 222, Experiment 502, 


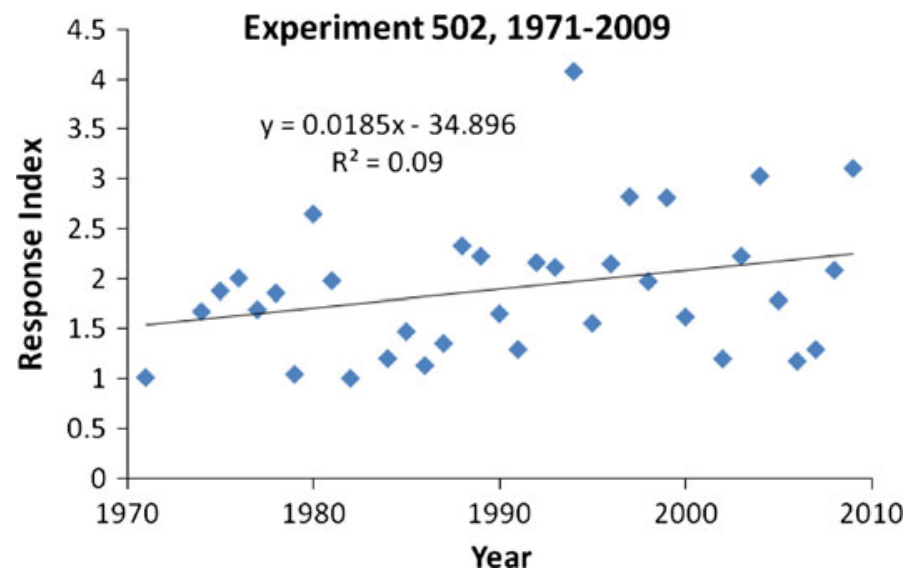

Fig. 7 Relationship between the response index and time (year) for the long-term wheat Experiment 502, near Lahoma, OK, 1970-2008

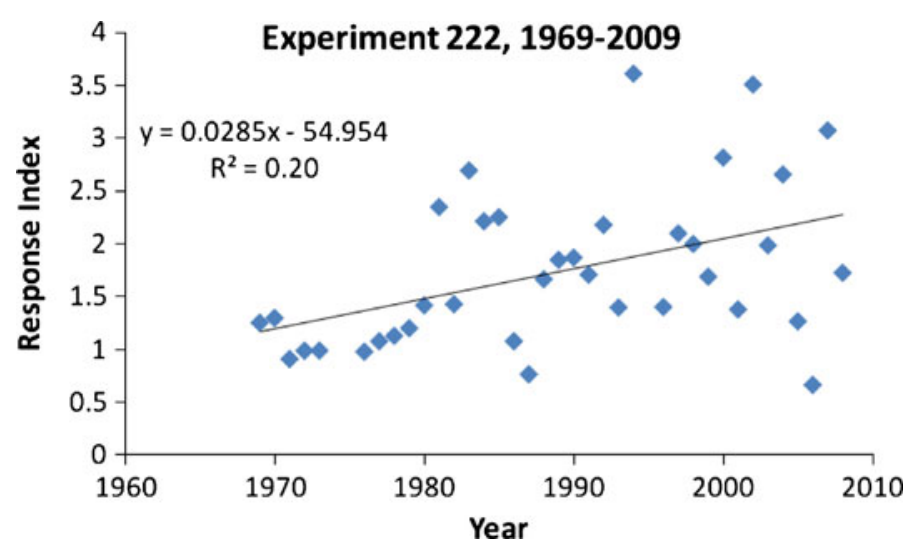

Fig. 8 Relationship between the response index and time (year) for the long-term winter wheat Experiment 222, Stillwater, OK, 1969-2008

and Mead, NE, respectively). Thus, with knowledge of such wide differences in $\mathrm{N}$ demand, would farmers apply the same rate of $\mathrm{N}$ each year? These results and those from other long-term trials demonstrate the wide differences in $\mathrm{N}$ demand, and the need to apply fertilizer based on independent assessments of yield potential and $\mathrm{N}$ responsiveness. Applying a fixed rate of fertilizer each year, or a rate based on a sufficiency value that does not compensate for predicted yield levels is, therefore, considered problematic.

Because of the wide differences in $\mathrm{N}$ demand, these results address a separate issue, and that is whether or not $\mathrm{N}$ rich strips are needed in general each year. Without the $\mathrm{N}$ rich strip, it would have been impossible to determine that $\mathrm{N}$ demand fluctuated over time (Figs. 7, 8, 9). Furthermore, it would not be possible to estimate the RI because the non$\mathrm{N}$-limiting plot is critical for determining $\mathrm{N}$ responsiveness. Recent claims that suggest $\mathrm{N}$ rich strips are not needed and that NDVI readings can be estimated virtually are cause for concern. If the limiting nutrient was not verified and optimum growth not related to repeatable conditions, interpretation of the final effect $(\mathrm{N}, \mathrm{P}, \mathrm{K}, \mathrm{S}$, etc. demand) could be 


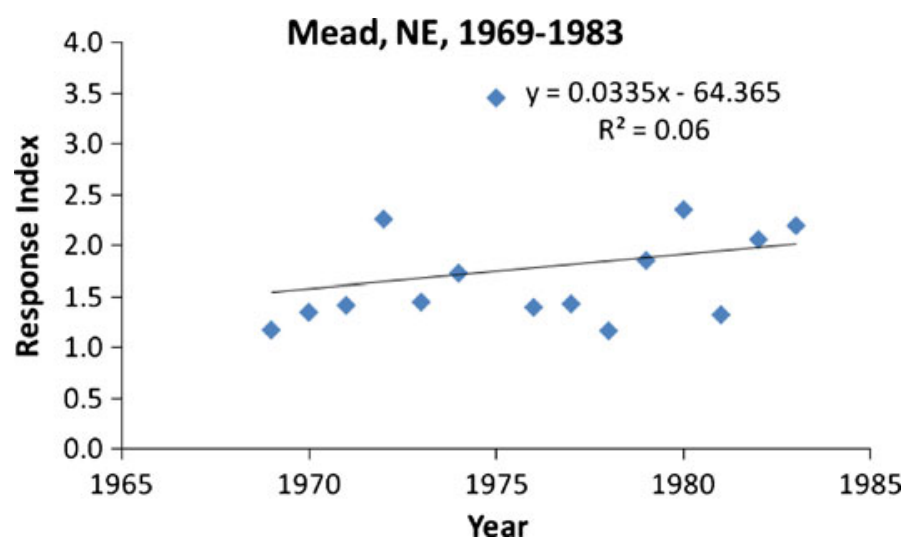

Fig. 9 Relationship between the response index and time (year) for the long-term corn experiment at Mead, NE, 1969-1983

incorrect. Liebig's law of the limiting nutrient is still in place today and will be the case well into the future. Determining the demand for fertilizer $\mathrm{N}$ without an $\mathrm{N}$ rich strip is not recommended. Furthermore, the process of determining which element is needed can only be achieved with paired comparisons of the field rate of an element and an immediately adjacent non-limiting rate.

This study showed that $\mathrm{N}$ responsiveness (response index) and grain yield were not related in three long-term experiments. There was no relationship between yield and year at two of three sites, and no relationship between $\mathrm{N}$ responsiveness and year at any site. The independence of $\mathrm{N}$ responsiveness and yield shows why $\mathrm{N}$ rates cannot be based on one or the other, but they must combine both to arrive at realistic in-season $\mathrm{N}$ rates.

\section{Conclusions}

It is well understood that crop yield and $\mathrm{N}$ responsiveness affect the demand for fertilizer nitrogen, but how these two are related has not been reported previously. No relationship between $\mathrm{N}$ responsiveness and grain yield was found in the three long-term wheat and corn experiments evaluated. Furthermore, yield and year were not related at two of three sites and there was no relationship between $\mathrm{N}$ responsiveness and year at any site. Because yield and $\mathrm{N}$ responsiveness were consistently independent of one another and as both affect the demand for fertilizer $\mathrm{N}$, estimates of both should be combined to calculate realistic in-season $\mathrm{N}$ rates.

\section{References}

Bray, R. H. (1954). A nutrient mobility concept of soil-plant relationships. Soil Science, 78, 9-22.

Bray, R. H. (1962). Confirmation of the nutrient mobility concept of soil-plant relationships. Soil Science, $86,124-130$.

Girma, K., Freeman, K. W., Teal, R., Arnall, D. B., Tubana, B., Holtz, S., et al. (2007a). Analysis of yield variability in winter wheat due to temporal variability, and nitrogen and phosphorus fertilization. Archives Agronomy and Soil Science, 53, 435-442. 
Girma, K., Holtz, S. L., Arnall, D. B., Fultz, L. M., Hanks, T. L., Lawles, K. D., et al. (2007b). Weather, fertilizer, previous year grain yield and fertilizer response level affect ensuing year grain yield and fertilizer response of winter wheat. Agronomy Journal, 99, 1607-1614.

Girma, Kefyalew, Martin, K. L., Anderson, R. H., Arnall, D. B., Brixey, K. D., Casillas, M. A., et al. (2006). Mid-season prediction of wheat grain yield potential using plant, soil, and sensor measurements. Journal of Plant Nutrition, 29, 873-897.

Hochheim, K. P., \& Barber, D. G. (1998). Spring wheat yield estimation for western Canada using NOAA NDVI data. Canadian Journal of Remote Sensing, 24, 17-27.

Johnson, G. V., \& Raun, W. R. (2003). Nitrogen response index as a guide to fertilizer management. Journal of Plant Nutrition, 26, 249-262.

Lukina, E. V., Freeman, K. W., Wynn, K. J., Thomason, W. E., Mullen, R. W., Klatt, A. R., et al. (2001). Nitrogen fertilization optimization algorithm based on in-season estimates of yield and plant nitrogen uptake. Journal of Plant Nutrition, 24, 885-898.

Mullen, R. W., Freeman, K. W., Raun, W. R., Johnson, G. V., Stone, M. L., \& Solie, J. B. (2003). Identifying an in-season response index and the potential to increase wheat yield with nitrogen. Agronomy Journal, 95, 347-351.

Olson, R. A., Raun, W. R., Chun, Y. S., \& Skopp, J. (1986). Nitrogen management and interseeding effects on irrigated corn and sorghum and on soil strength. Agronomy Journal, 78, 856-862.

Raun, W. R., Johnson, G. V., Stone, M. L., Solie, J. B., Lukina, E. V., Thomason, E. V., et al. (2001). Inseason prediction of potential grain yield in winter wheat using canopy reflectance. Agronomy Journal, 93, 131-138.

Raun, W. R., Solie, J. B., Johnson, G. V., Stone, M. L., Mullen, R. W., Freeman, K. W., et al. (2002). Improving nitrogen use efficiency in cereal grain production with optical sensing and variable rate application. Agronomy Journal, 94, 815-820.

Raun, W. R., Solie, J. B., Stone, M. L., Martin, K. L., Freeman, K. W., Mullen, R. W., et al. (2005). Optical sensor based algorithm for crop nitrogen fertilization. Communications in Soil Science and Plant Analysis, 36, 2759-2781.

Teal, R. K., Tubana, B., Girma, K., Freeman, K. W., Arnall, D. B., Walsh, O., et al. (2006). In-season prediction of corn grain yield potential using normalized difference vegetation index. Agronomy Journal, 98, 1488-1494.

Varvel, G. E., Wilhelm, W. W., Shanahan, J. F., \& Schepers, J. S. (2007). An algorithm for corn nitrogen recommendations using a chlorophyll meter based sufficiency index. Agronomy Journal, 99, 701-706. 